www.jmscr.igmpublication.org

Impact Factor 5.244

Index Copernicus Value: 83.27

ISSN (e)-2347-176x ISSN (p) 2455-0450

crossref DOI: https://dx.doi.org/10.18535/jmscr/v4i12.05

Journal Of Medical Science And Clinical Research

\title{
Congenital Ptosis - Reconstructive Surgery by Occipitofrontalis Muscle Transfer
}

Authors

M.Radhakrishnan', Edwin Emperor Cyril Raj ${ }^{2}$, Ahamed Rafeeq Meeran³, Manimegalai Radhakrishnan ${ }^{4}$, Suja $S R^{5}$, Leeja Latheef $L^{6}$

${ }^{1}$ Professor and HOD, Dept of Plastic and Reconstructive Surgery, Kanyakumari Government Medical

College, Asaripallam, Nagercoil, Tamilnadu, India

${ }^{2}$ Associate Professor, Dept of Plastic and Reconstructive Surgery, Kanyakumari Government Medical

College, Asaripallam, Nagercoil, Tamilnadu, India

${ }^{3}$ Assistant Professor, Dept of Plastic and Reconstructive Surgery, Kanyakumari Government Medical

College, Asaripallam, Nagercoil, Tamilnadu, India

${ }^{4}$ Consultant gynaecologist, ML plastic and gynaec Hospital

${ }^{5}$ Assistant Professor, Dept of Biochemistry, Indira Gandhi Government Medical College,

Thiruvananthapuram

${ }^{6}$ Assistant Professor, Department of Microbiology, Kannur Medical College, Kannur

\section{INTRODUCTION}

\section{ANATOMY}

\section{OCCIPITOFRONTALIS MUSCLE}

Occipitofrontalis covers the dome of the skull from the highest nuchal lines of the eyebrows. It is a broad, musculofibrous layer and consists of four thin, muscular quadrilateral parts, two occipital and two frontal, connected by the epicranial aponeurosis. Each occipital part (occipitalis) arises by tendinous fibres from the lateral twothirds of the highest nuchal line of the occipital bone and the adjacent region of the mastoid part of the temporal bone, and extends forward to join the aponeurosis. The gap between the occipital parts is occupied by an extension of the epicranial aponeurosis. Each frontal part (frontalis) is adherent to the superficial fascia, particularly of the eyebrows. Although frontalois has no bony attachments of its own, its fibres blend with those of adjacent muscles-procerus, corrugators supercilii and orbicularis oculi- and ascend to join the epicranial aponeurosis in front of the coronal suture.

\section{Vascular supply}

Occipitofrontalis is supplied by branches of the superficial temporal, ophthalmic, posterior auricular and occipital arteries.

\section{Innervation}

The occipital part of occipitofrontalis is supplied by the posterior auricular branch of the facial nerve and the frontal part is supplied by the temporal branches of the facial nerve.

\section{Actions}

Acting from above, the frontal part raise the eyebrows and the skin over the root of the nose 
(e.g. as in expressions of surprise or horror). Acting from below, the frontal parts draw the scalp forwards, throwing the forehead into transverse wrinkles. The occipital parts draw the scalp backwards. Acting alternately, the occipital and frontal parts can move the entire scalp backwards and forwards.

\section{Variations}

A thin muscular slip, transverses nuchae, is present in $25 \%$ of people. It arises from the external occipital protuberance or from the superior nuchal line, either superficial or deep to trapezius. It is frequently inserted with auricularis posterior, but may blend with the posterior edge of sternocleidomastoid.

\section{LEVATOR PALPEBRAE SUPERIORIS MUSCLE}

Levator palpebrae superioris is a thin, triangular muscle which arises from the inferior aspect of the lesser wing of sphenoid, above and in front of the optic canal, and separated from it by the attachment of superior rectus. It has a short narrow tendon at its posterior attachment, and broadens gradually, then more sharply as it passes anteriorly above the eyeball. The muscle ends in front in a wide aponeurosis. Some of its tendinoud fibres pass straight into the upper eyelid to attach to the anterior surface of the tarsus, while the rest radiate and pierce orbicularis oculi to pass to the skin of the upper eyelid. A thin lamina of smooth muscle, the superior tarsal muscle, passes from the underside of levator palpebrae superioris to the upper margin of the superior tarsus.

The connective tissue sheats of the adjoining surfaces of levator palpebrae superioris and superior rectus are fused. Where the two muscles separate to reach their anterior attachments, the fascia between them forms a thick mass to which the superior conjunctival fornix is attached: this is usually described as an additional attachment of levator palpebrae superioris. Traced laterally, the aponeurosis of the levator passes between the orbital and palpebral parts of the lacrimal gland to attach to the orbital tubercle of the zygomatic bone. Traced medially, it loses its tendinous nature as it passes closely over the reflected tendon of superior oblique, and continues on to the medial palpebral ligament as loose strands of connective tissue.

\section{Vascular supply}

Levator palpebrae superioris receives its arterial supply both directly from the ophthalmic artery and indirectly from its supraorbital branch.

\section{Innervation}

Levator palpebrae superioris is innervated by a branch of the superior division of the oculomotor nerve which enters the inferior surface of the muscle. Sympathetic fibres to the smooth muscle component of levator palpebrae superioris (superior tarsal muscle) are derived from the plexus surrounding the internal carotid artery; these nerve fibres may join the oculomotor nerve in the cavernous sinus and pass forward in its superior branch.

\section{Actions}

Levator palpebrae superioris elevates the upper eyelid. During this process the lateral and medial parts of its aponeurosis are stretched and thus limits its action: the elevation is also checked by the orbital septum. Elevation of the eyelid is opposed by the palpebral part of orbicularis oculi. Levator palpebrae superioris is linked to superior rectus by a check ligament, thus the upper eyelid elevates when the gaze of the eye is directed upwards.

The position of the eyelids depends on reciprocal tone in orbicularis oculi and levator palpebrae superioris, and on the degree of ocular protrusion. In the opened position the upper eyelid covers the upper part of the cornea, while the lower lid lies just below its lower margin. The eyes are closed by movements of both lids, produced by the contraction of the palpebral part of orbicularis oculi and relaxation of levator palpebrae superioris. In looking upwards, the levator contracts and the upper eyelid follows the ocular movement. At the same time, the eyebrows are usually raised by the frontal parts of occipitofrontalis to diminish their overhang. The 
lower lid lags behind ocular movement, so that more sclera is exposed below the cornea and the lid is bulged a little by the lower part of the elevated eye. When the eye is depressed both lids move: the upper retains its normal relation to the eyeball and still covers about a quarter of the cornea, whereas the lower lid is depressed because the extension of the thickened fascia of inferior rectus and inferior oblique pull on its tarsus as the former contracts.

The palpebral apertures are widened in states of fear or excitement by contraction of the smooth muscle of the superior and inferior tarsal muscles as a result of increased sympathetic activity. Lesions of the sympathetic supply result in drooping of the upper eyelid (ptosis), as seen in Horner's syndrome.

\section{MATERIALS AND METHODS}

A study was done on ten cases of congenital ptosis, surgically managed at Dept of Plastic and Reconstructive Surgery, Kanyakumari Government Medical College, Asaripallam, Nagercoil, Kanyakumari district, Tamilnadu, India from January 2014 to December 2015.

\section{DEFINITION}

Drooping of upper eyelid during normal forward gaze.

It is due to absent or insufficient action of the levator palpebrae superioris.

It may or may not be associated with paralysis of superior rectus muscle.

\section{SPAETH CLASSIFICATION OF PTOSIS: CONGENITAL PTOSIS}
a) Unilateral without involvement of superior rectus muscle
b) Unilateral with involvement of the homolateral superior rectus muscle.
c) Bilateral without involvement of the superior rectus muscle
d) Bilateral with involvement of superior rectus muscle
e) Ptosis with paralysis of iii or vi cranial nerve
f) Ptosis with jaw-winking reflex.
g) Ptosis with duane's retraction syndrome
h) Ptosis with neurofirromatosis

\section{ACQUIRED PTOSIS}
a) Traumatic (peripheral, cicatricial)
b) Traumatic (central \& cerebrospinal)
c) Third nerve paralysis
d) Third nerve regenerating fibers (pseudo graffe syndrome)
e) Cervical sympathetic paralysis
f) Atonic ptosis (senile)
g) Neuromuscular
h) Regenerative (blepharochalasis)
i) Neoplastic
j) Hysterical

\section{SURGICAL TREATMENT}

AIM
COSMETIC
$>$ FUNCTIONAL

\section{CLASSIFICATION OF OPERATIVE PROCEDURES}

1. Shortening or Advancement of LPS

2. Utilisation of Action of Superior Rectus

3. Utilisation of Fascia Graft (Fascia Lata) To Transfer The Action of Frontalis to The Upper Eyelid to Elevate It.

\section{SELECTION OF THE PROCEDURE}

It Is According To

1. The Cause

2. Nature

3. Type In The Classification

4. Familiarity of the Procedure by $\mathrm{Th}$ Surgeons.

Most of the Above Operations Can Produce Improvement or Even Satisfactory Results in Mild Ptosis. None Is Entirely Satisfactory for the Severe Cases. 


\section{DIAGRAMATIC REPRESENTATION \& OPERATIVE PHOTOS}
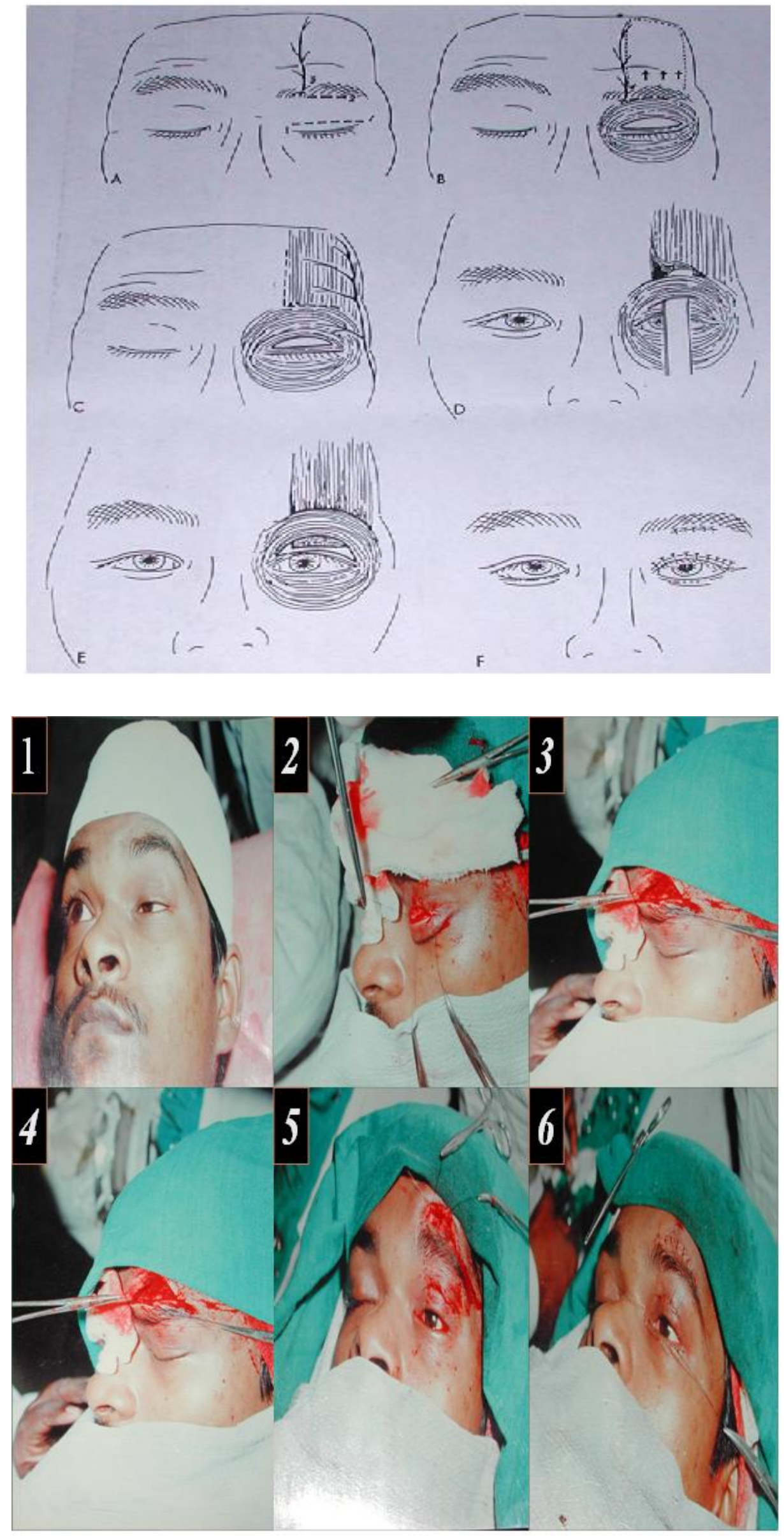


\section{FRONTALIS MUSCLE TRANS}

In Severe Cases Frontalis Contracts Forcefully In A Vain Attempt To Lift The Upper Eyelid Dr. Ruyao Song And Dr.Yeming Song In 1962 Transfered Directly The Frontalis Muscle To The Drooping Upper Eyelid With Excellent Result.

\section{IMPORTANT POINTS IN FRONTALIS MUSCLE TRANSFER}

A. Action of Frontalis Muscle Must Be Present.

B. Incision Made $1 \mathrm{~cm}$ From The Lashes And Parallel To The Lid Margin.

C. Frontalis Muscle Freed Through Infrabro Incision.

D. Freed Frontalis Muscle Transferred To The Anterior Surface Of Tarsal Plate By Passing It Deep To Orbicularis Oculi \& Fixed To The Tarsal Plate With 6 - O Vicryl.

\section{OUR EXPERIENCE WITH FRONTALIS} MUSCLE TRANSFER

During The Period of 1 Year $(2014-2015)$ We Have Operated 10 Cases Of Severe Ptosis By Direct Frontalis Muscle Transfer With Overall Good Results.

\section{PROBLEMS ENCOUNTERED}

\section{ENTROPION (2 CASES)}

Entropion Was Rectified In Both The Cases By Excising Excess Skin And Orbicularis Oculi.

2. NOTCHING OF THE LID MARGIN (1 CASE) :

Notching Of The Lid Margin We Advised Massaging Of The Eyelid.

\section{PARTIAL CORRECTION (1 CASE):}

Partial Correction In 1 Case Was Accepted Since The Patient Was Operated Many Times Previously And Landed Here With Complete Ptosis.
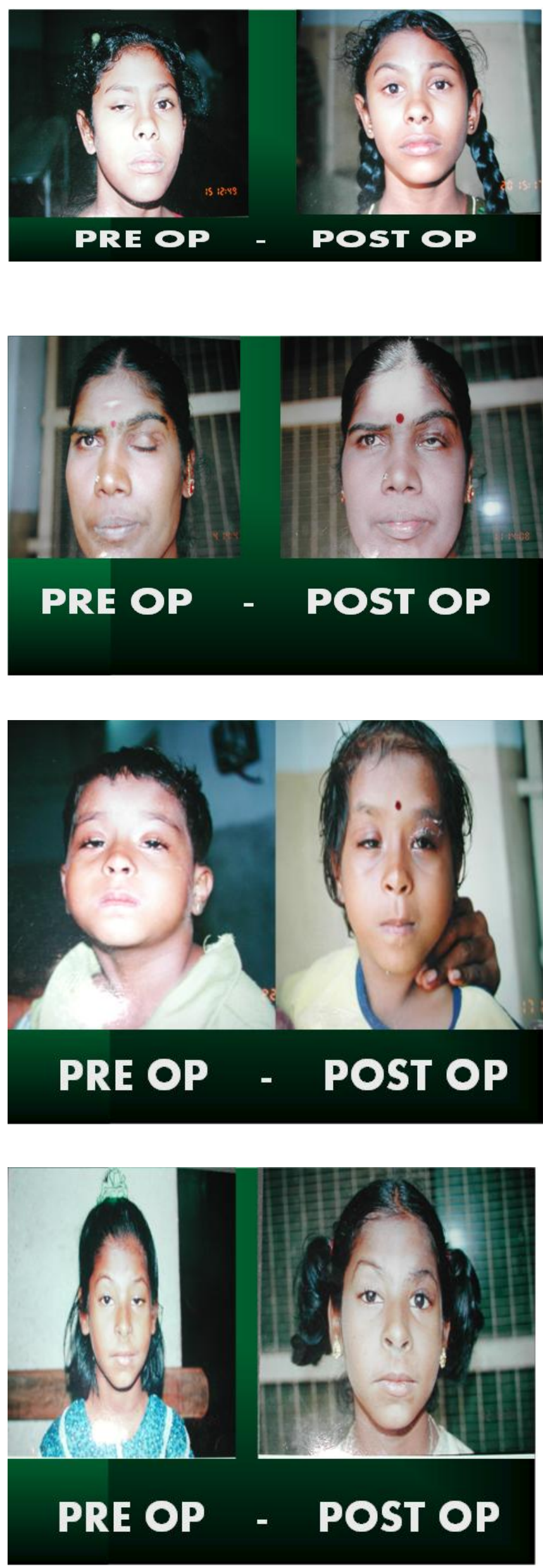


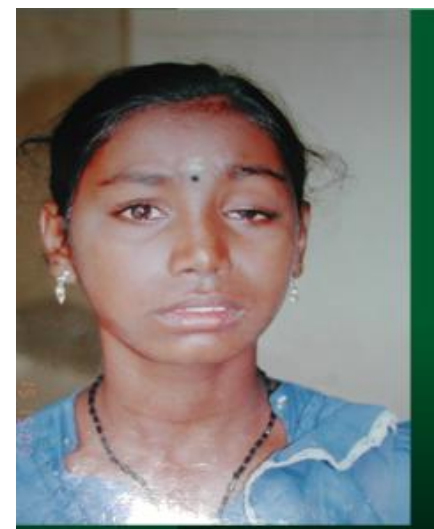

PRE OP - POST OP

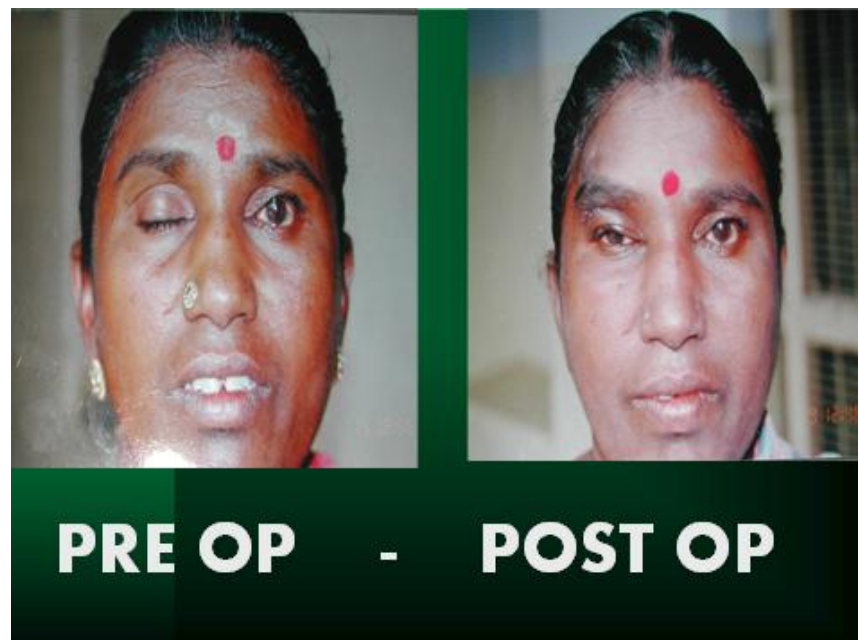

DISCUSSION

DIRECT FRONTALIS MUSCLE TRANSFER HAS FOLLOWING MERITS

1. Lowered Margin Of The Frontalis Muscle Sutured To The Tarsal Plate Heals Well And Firm \& Permanent Anchorage Obtained.

2. Deep Wrinkles In The Forehead Disappears.

3. Supratarsal Eyelid Fold After This Procedure Gives A Normal Appearance To The Eyelid To The Entire Satisfaction.

4. This Procedure Being Dynamic In Nature Produces Permanent Correction Unlike Other Surgical Corrections.
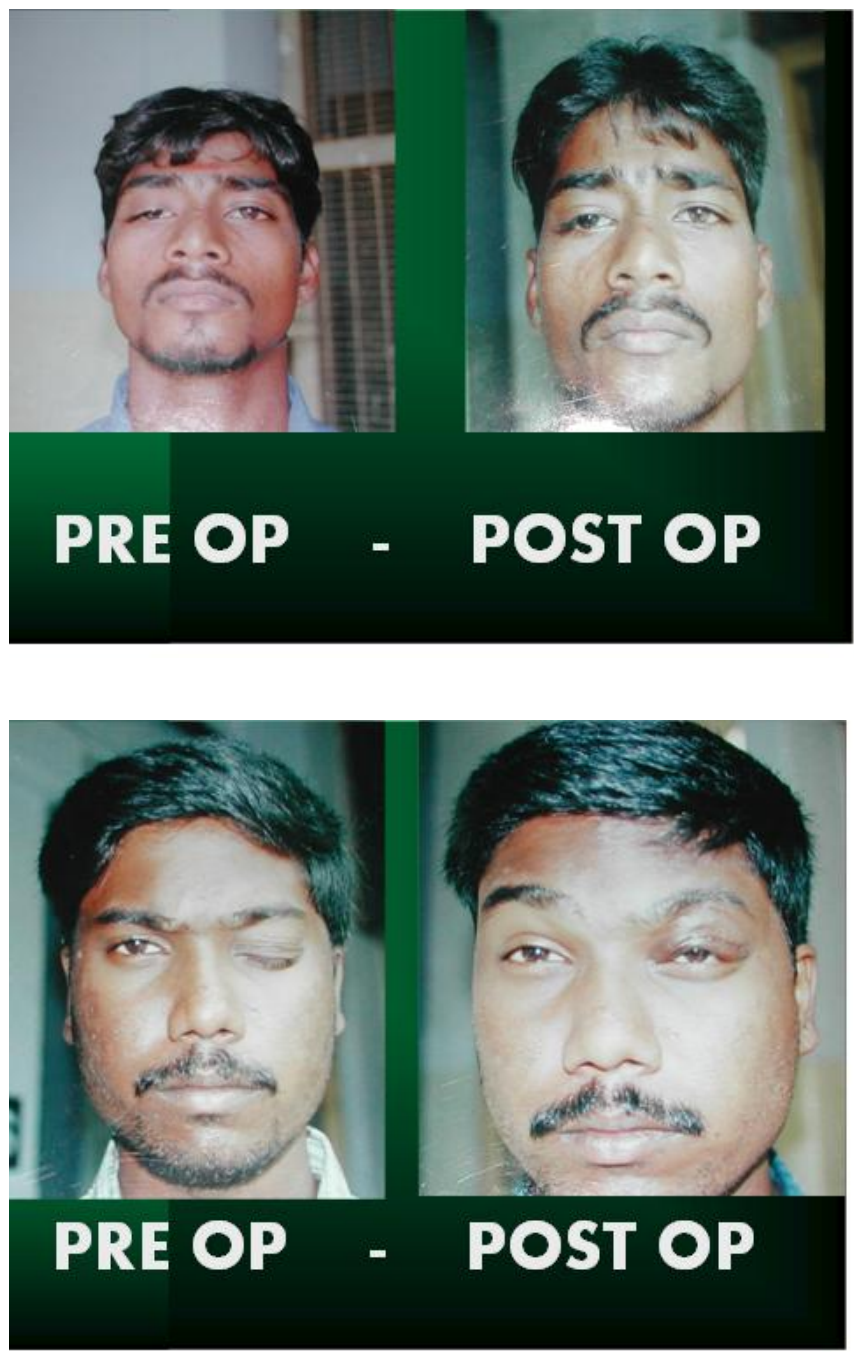

\section{REFERENCES}

1. Modified Staged Surgical Intervention for Blepharophimosis-Ptosis-Epicanthus Inversus Syndrome: 125 Cases With Encouraging Results

2. Song, Xin MD, $\mathrm{PhD}^{*}$; Jia, Renbing MD, PhD*; Zhu, Huimin MD*; Zhou, Yixiong $\mathrm{MD}, \mathrm{PhD}^{*}$; $\quad$ Sun, Ying MD*; Lin, Ming MD*; Fu, Yao MD, $\mathrm{PhD}^{*}$; Li, Jin MD, $\mathrm{PhD}^{*}$; Li, Zhengkang MD*; Lu, Linna $\mathrm{MD}^{*}$; Shen, Yundun $\mathrm{MD}^{\dagger}$; Ge, Shengfang $\mathrm{PhD}^{*}$; Fan, Xianqun MD, $\mathrm{PhD}^{*}$

3. Frontalis Muscle Advancement: A Dynamic Structure for the Treatment of Severe Congenital Eyelid Ptosis Ramirez, Oscar M. M.D.; Peña, Guillermo M.D. Ptosis Surgery: Past, Present, and Future.Beard, Crowell M.D 
4. Various Modifications of Müller's MuscleConjunctival Resection for Ptosis Repair, Shu-Lang Liao, ${ }^{1}$ and Ann Yi-chiun Chuang $\otimes^{2}$ Department of Ophthalmology, National Taiwan University Hospital, Taipei, Taiwan, Department of Ophthalmology, Mackay Memorial Hospital, Taipei, Taiwan.

5. A One-Stage Correction of the Blepharophimosis Syndrome Using a Standard Combination of Surgical Techniques Sebastiá, R., Herzog Neto, G., Fallico, E. et al. Aesth Plast Surg (2011) 